\title{
12. (Pathologies of) Recognition in Schelling's Thought on Evil
}

\section{by Olli Pitkänen}

\section{Introduction}

In his article 'Jihad vs. McWorld' Benjamin Barber utilizes the terms 'Jihad' and 'McWorld' to describe 'two possible political futures - both bleak, neither democratic' (Barber, 1992, 1). He categorizes McWorld through four imperatives, all of which aim at universality and globality in the name of democracy and human rights: (1) the market imperative aiming at a global free market, (2) the resource imperative aiming at entrance to resources all around the world, (3) the information-technology imperative aiming at global networks of information, entertainment and technology, (4) the ecological imperative treating nature as a reservoir to use and control (Barber, 1992, 1-5). According to Barber, McWorld:

is being borne in on us by the onrush of economic and ecological forces that demand integration and uniformity and that mesmerize the world with fast music, fast computers, and fast food - with MTV, Macintosh, and McDonald's, pressing nations into one commercially homogenous global network: one McWorld tied together by technology, ecology, communications, and commerce. (Barber, 1992, 1)

Jihad, instead, is presented as the antithesis of McWorld. Actually Jihad is anything but one consistent ideology. It means:

a retribalization of large swaths of humankind by war and bloodshed: a threatened Lebanonization of national states in which culture is pitted against culture, people against people, tribe against tribe - a Jihad in the name of a hundred narrowly conceived faiths against every kind of interdependence, every kind of artificial social cooperation and civic mutuality. (Barber, 1992, 1)

Most likely the only unifying factor behind the groups Barber labels under the banner 'Jihad' is a fanatical opposition to McWorld's globalism which is 
conceived as the most fundamental threat to a tradition every particular 'jihadist' represents. Instead of groups, movements or any similar description, Jihad and McWorld could best be described as mentalities or mindsets. McWorld represents an expansive mentality whose explicit commitment is to spread the ideals of democracy, tolerance and human rights, perhaps even by force if necessary; Jihad instead is contractive. It looks only inside its own tradition, and in defending it sees war 'not as an instrument of policy but as an emblem of identity, an expression of community, an end in itself' (Barber, 1992, 5).

Even if Barber can be legitimately accused of oversimplifying the complex political reality (see for example Metzl, 1996), the clash between Jihad and McWorld no doubt describes something essential about the current social reality. Since 1992 Barber's threat scenario has only become more and more relevant. An obvious demonstration of this is the 9/11 terror strike and the discourse that has followed it. Before 9/11 the general ethical atmosphere in the USA was dominated by a relativistic attitude: what some consider as evil is good for others and vice versa. However, after 9/11 the public atmosphere changed almost in one night to blatant objectivism: the strikes and the agents behind them were judged as unequivocally evil (Bernstein, 2008b, vii; Shafer-Landau, 2004, vii). On the other hand, those who were responsible for the strikes saw themselves as dedicated to a fight against evil. One possible conclusion to draw from this is that we should stop believing in moral absolutes such as evil. At least it is not rare that those who loudly judge something as evil tend to engage themselves in dreadful acts against their "evil" enemy (Garrard \& McNaughton, 2012, 2). My starting point, however, is that calling something evil is not necessarily a dehumanizing statement that means an end to all constructive discussion about the matter.

In what follows I read F.W.J. Schelling's theory of evil as a theory of recognition. First I present Schelling's metaphysical 'system of freedom' in his so called Freedom Essay, and the theory of evil related to it. Next I expound how Joseph Lawrence, in his article 'Schelling's Metaphysics of Evil' (2004), distinguishes two forms of evil in Schelling's theory, which he links to Barber's conceptions of Jihad and McWorld. Lastly, based on Lawrence's reading of Schelling, I argue that the clash between Jihad and McWorld is primarily one of recognition and not one of hopelessly incompatible values and interests. I take Schelling's theory to be especially insightful in depicting evil's relationship to self-deception. The animosity of Jihad and McWorld is based on the 'bad faith' of each party, and finding an external enemy is an efficient way of hiding this. Therefore, the 'Schellingian theory of recognition' is in equal measure a theory of self-recognition. 


\section{The System of Freedom}

Schelling might seem an odd figure to take up when talking about practical social matters. While Kant, Hegel and Fichte have for a long time been read as highly relevant thinkers for contemporary issues, Schelling has been traditionally presented primarily as a mediator between the subjective idealism of Fichte and the absolute idealism of Hegel (Lawrence, 2005, 13). It has been common to almost entirely disregard Schelling's later philosophy, where he drew lots of influences from unorthodox sources such as Böhme's theosophy and Lurianic Kabbalah (McGrath 2012, 46). For example, according to John Watson, the later stage of Schelling's thought 'gives us not philosophy but poetry' (Watson, 2004, 249).

However, in recent decades a 'Schelling renaissance' has appeared; commentators from various viewpoints have judged Schelling's thought as highly original and worthy of serious study on its own (Norman \& Welchman, 2004, 1-11; Ostaric, 2014, 2-4; Wirth, 2005, 5-9). Schelling's creativity has been recognized in fields as diverse as ontology of nature (Grant, 2008, 2-3; McGrath, 2012, 83-106; Žižek, 2007, 220-231), deep ecology (Bernstein, 2008a, 92; Hösle, 1992, 166-197; Pylkkö, 2004, 214-215), psychoanalysis (Bowie, 2006, 96-97; Ffytche, 2013, 4-7; Marquard, 2004, 1329; McGrath, 2012, 1), and cultural anthropology (Habermas, 2004, 43-89; Lawrence, 2004, 167-189). To sum up, according to Jason Wirth:

Schelling is better construed not as the already sublimated objective counterpart to Fichte, a loopy mystic, or as an antiquated theologian but rather as the belated contemporary of thinkers like Heidegger, Derrida, Bataille, Irigaray, Foucault, Deleuze, Levinas, and many others. (Wirth 2005, 6)

The new appreciation of Schelling's thought relates mostly to his tendency to question certain widely accepted assumptions in Western philosophical traditions, thereby introducing viewpoints and solutions that few have come to. It is often thought that Schelling's solutions as such may not be plausible today, but that he has an astonishing ability to provoke further thought. According to Iain Hamilton Grant, 'Schelling is not a forerunner of anything, but a precursor of philosophical solutions [...] yet to come' (Grant, 2008, 205). In a similar vein, Bernard Freydberg calls Schelling's core ideas 'provocations' and conceives Schelling as a 'timeless' thinker whose 'thought is required when the philosophical landscape seems most eviscerated' (Freydberg, 2008, 113). Some of Schelling's main ideas are hard to locate in the continuum of Western philosophy, to the extent that Pauli Pylkkö even calls Schelling 'a trauma of the history of philosophy' (Pylkkö, 2004, 150). 
Slavoj Žižek puts Schelling's peculiarity in the following way:

Therein consists the unique intermediate position of Schelling, his double non-contemporaneity to his own time: he belongs to three discursive domains - he simultaneously, as it were, speaks three languages: the language of speculative idealism; the language of anthropomorphic-mystical theosophy; the postidealist language of contingency and finitude. The paradox, of course, is that it was his very 'regression' from pure philosophical idealism to pre-modern theosophical problematic which enabled him to overtake modernity itself. ${ }^{1}$ (Žižek 2007, 8)

In this respect, one of Schelling's most appreciated works is the essay 'Philosophical Inquiries into the Nature of Human Freedom' from 1809, known as the 'Freedom Essay.' In this treatise Schelling takes up the perennial questions of freedom and evil. His central argument is that in order to conceive of human freedom and evil in an appropriate way, existence itself must be conceived in a new way - 'more primordially, as Heidegger (1985, 103) puts it - compared to the mainstream Western philosophical tradition since Aristotle. The recent background against which Schelling presents his position is, on the one hand, in Kant's revolutionary critical philosophy, and on the other hand in the so called pantheism controversy.

The pantheism controversy took place at the end of the $18^{\text {th }}$ century when Gotthold Lessing, seemingly a 'good Christian,' confessed that he actually favors Spinoza's pantheistic view of God. At the time Spinoza was a highly notorious figure, his name being associated with 'atheism, fatalism, nihilism, and moral decadence' (Wirth, 2003, 34). According to Spinoza, all beings belong to God, and because God is the highest totality of everything, everything derives from God with absolute necessity. It was claimed that pantheism is actually equivalent to atheism because in pantheism there is no difference between God and created beings. This in turn leads, it was argued, to fatalism because nature is causally determined, and without a spiritual source outside it man as a part of nature would be reduced to its causal mechanisms (Wirth, 2003, 33-44)

Schelling admits that 'the fatalistic point of view can be combined with pantheism,' but he also claims that 'many are driven to this pantheistic outlook precisely because of the liveliest sense of freedom' (Schelling, 1992, 10). In Schelling's view, belonging to something as such does not mean that a part cannot have freedom of its own in the whole it belongs to. Schelling demonstrates this by analogy to the human body:

A single organ, like the eye, is possible only in the organism as 
a whole; nevertheless it has a life of its own, indeed a kind of freedom, as is manifestly proved through those diseases to which it is subject. (Schelling, 1992, 19)

Moreover, if freedom cannot be compatible with pantheism, it seems strange that adding a God external to the system of nature would help the situation; everything would still ultimately be up to almighty God's will (Schelling, 1992, 10-11). Therefore, the reason for Spinoza's fatalism cannot be in pantheism as such:

The error of his system is by no means due to the fact that he posits all things in God, but to the fact that they are things - to the abstract conception of the world and its creatures, indeed of eternal Substance itself, which is also a thing for him. (Schelling, 1992, 22)

The fatalism in Spinoza's thought is caused by his mechanistic conception of nature. For Spinoza, nature consists in things and the causal mechanisms between them. According to Schelling, the will is also a causally determined thing for Spinoza, which then leads to a denial of any substantial view of freedom (Schelling, 1992, 22).

In Schelling's view, a lively conception of freedom requires a radical break with classical Western metaphysics since Aristotle. All that exists is usually taken as the sum-total of things under a set of given laws. God has been either simply equated with this totality or thought of as the 'unmoved mover' behind it. Schelling begins with the claim that everything that exists must have a ground for its existence, and this must apply even to God. However, 'as there is nothing before or outside of God he must contain within himself the ground of his existence' (Schelling, 1992, 32). According to Schelling, 'all philosophies say this, but they speak of this ground as a mere concept without making it something real and actual' (Schelling, 1992, 32). Schelling then asserts his own view of the ground in the following way:

This ground of his existence, which God contains [within himself], is not God viewed as absolute, that is insofar as he exists. For it is only the basis of his existence, it is nature -in God, inseparable from him, to be sure, but nevertheless distinguishable from him. (Schelling, 1992, 32)

God's ground is nature, however not in the sense of the object of sciences, but precisely in the sense of something unknown and unpredictable to man, and even to God himself. The ground can be conceived of as God's unconscious 
(McGrath, 2012, 151). In Schelling's view, this strange-sounding idea is needed in order to make intelligible how anything living can appear:

First, the concept of immanence is completely to be set aside insofar as it is meant to express a dead conceptual inclusion of things in God. We recognize, rather, that the concept of becoming is the only one adequate to the nature of things. But the process of their becoming cannot be in God, viewed absolutely, since they are distinct from him toto genere or - more accurately - in eternity. To be separate from God they would have to carry on this becoming on a basis different from him. But since there can be nothing outside God, this contradiction can only be solved by things having their basis in that within God which is not God himself, i.e. in that which is the basis of his existence. (Schelling 1992, 33)

If God was conceived of merely as the sum total of all things in the cosmos and their lawful order, or as the architect of this order outside the cosmos, it would be impossible to understand how anything new could be produced in nature. Nature would just run through its mechanical course or would be something analogical to a theatre performance directed by God. In other words, without the ground, existence would be a mere formula without actuality. The ground represents a chaotic element within order, and is responsible for the endless variety in everything. For example, if there are general laws governing how a certain kind of flower grows, how it functions, what its definite characteristics are etc., the ground makes it possible that every single flower is still an individual of its own, not to mention the huge number of different flower species and the endless variety of species still coming into existence. Order is impossible to conceive without the idea of chaos. On the other hand, chaos is impossible to conceive of as actually existing. Therefore, the ground does not actually exist; it is longing for existence.

The fundamental counterintuitive assumption of the Freedom Essay can thereby be summarized in the idea that existence is preceded by blind longing for existence, 'the longing which the eternal One feels to give birth to itself' (Schelling, 1992, 34). Paradoxical as this idea is (how can something that does not exist long for existence?), the traditional view of the merely causal-temporal ground ending in the first uncaused cause does not seem to be any less paradoxical. Žižek (2007, 220-231) has aptly noticed that Schelling's metaphysics is compatible with the paradoxical sounding results of modern physics. The story is often told that first there was nothing, and then, at one moment, the lawful universe was born in the Big Bang. However, 
since there was no time and space "before" the Big Bang, there could not be "a moment" when the Big Bang took place. The becoming of the universe therefore seems to involve a non-temporal element like Schelling's idea of becoming from ground to existence.

\section{Schelling's Theory of Evil}

Although Schelling's metaphysical 'system of freedom' is highly abstract, its main motivation is in an adequate practical understanding of evil, which could escape the two extremes of explaining evil away and conceiving it as an independent force, entirely distinct from the good (Welchman, 2013, 2728). God in his actual existence bends the ground to serve merely as the ground for the existing order, but God's unifying will of love can appear only if there is something to unify:

The spirit of love did not reveal itself at once in history, but God rather allowed the basis to operate independently, because he felt the will of the basis to be the will towards his revelation and recognized, in accordance with his providence, that a basis independent of him (as spirit) would have to be the basis of his existence. (Schelling, 1992, 55)

Because God's actual ordered existence is necessarily preceded by his dark and unruly ground, there is always the possibility of evil even in God. And because the ground precedes existence in a non-temporal sense, 'the unruly lies ever in the depths as though it might again break through, and order and form nowhere appear to have been original, but it seems as though what had initially been unruly had been brought to order' (Schelling, 1992, 34).

Actual evil instead of its mere possibility is then based on man's peculiar role in the cosmos. By his free will man can freely choose evil, that is, to invert the relation of ground and existence in himself: 'thus there takes place in man's will a division of his spiritualized selfhood from the light (as the spirit stands above light) - that is, a dissolution of the principles which in God are indissoluble' (Schelling, 1992, 40). Schelling always emphasizes that evil is spiritual, and thus that the possibility to choose evil constitutes man's essence as a free self-conscious being. Unlike the Augustinian tradition, Schelling argues that 'imperfection in the general metaphysical sense, is not the common character of evil, as it often manifests itself united with an excellence of individual powers which much less frequently accompanies the good' (Schelling, 1992, 44).

Keeping in mind the analogy between the cosmos and the human body, Schellingian evil is like a cancer. Cancer has an astonishing ability to 
grow compared to ordinary vital bodily functions. The negative aspect of this is that it tries to grow its own organism independently of the body it inhabits, and consequently, of course, destroys itself as well. An evil person is similar to cancer in that their pride tries to create a system of its own, not recognizing that however astonishing their creation is, it can be constructed only as a part of a system still far greater: that is, of the cosmic order as a whole (McGrath 2012, 72). Explicit evil consists in subordinating everything universal to one's selfhood and creativity based on the ground. However, Schelling $(1992,49)$ stresses that the ground as such can never be conceived of as evil. On the contrary, the ground is also operative when one strives to become a more perfect human being. The case is analogical to how scientists explore cancers in the hope of finding new kinds of treatments to other diseases. It is only the wrong subordination of existence and its ground that counts as disharmony, as illustrated by David Roberts through an analogy to a hybrid made by joining parts of different animals together in an ingenious yet monstrous way (Roberts 2006, 16).

\section{The Dynamics of Social Evil by Lawrence}

In his article 'Schelling's Metaphysics of Evil' (2004) Joseph Lawrence illustrates Schelling's theory of evil by interpreting Barber's notions of Jihad and McWorld in the framework of Schelling's metaphysics. Lawrence begins by noticing that in our contemporary Western culture, there are two different popular views of evil of which the first is dominant for most of the time. Both views deny evil as a part of our meaningful reality. More often evil is thought to be virtually non-existent, 'a holdover from a mythical, Christian worldview whose time was already past' (Svendsen, 2010, 9), or as Lawrence puts it: 'evil is [conceived of as] little more than an unfortunate residue of our animal heritage, the survival of aggressive instincts that can ultimately be overcome by reason" (Lawrence, 2004, 170). On the other hand, when a crisis that is serious enough appears (for example the 9/11 terror strike), evil is affirmed as a reality that stops all constructive discussion. The motivations of the evil perpetrators are thought of as completely unintelligible.

The view of evil as totally incomprehensible and demonic seems at first to have nothing to do with the rationalistic explaining away of evil. Yet Lawrence (2004, 169-170) makes an apt observation: where does the need to explain everything rationally (including especially evil) arise if not from a more fundamental fear that the reality itself is ultimately irrational, and that without taking it into rational control it would threaten to destroy all meaning? In Lawrence's words, 'metaphysical irrationalism is thus the deep premise of modern rationalism' (Lawrence, 2004, 170). Evil is something that does not properly fit into the view of the world as a fully rational system, so 
the existence of evil has to be denied in the first place. On the other hand, the demonic conception of evil first of all assumes the existence of evil, but in refusing to understand evil at all actually also makes evil something that does not belong to the intelligible reality we share.

Lawrence proceeds to another paradoxical turn: the two ways of denying evil, presented above, lead easily to two corresponding forms of evil. These forms of evil are what Barber calls McWorld and Jihad, 'the narcosis of a mechanized and endlessly self-duplicating form of reason' and 'the irrationally frenzied grip on tradition' (Lawrence, 2004, 168). Lawrence's argument is that Barber's analysis of Jihad and McWorld fits strikingly well with Schelling's metaphysics of evil. Schelling's conception of evil is ontological: evil is present as a possibility already at the heart of existence. All order can be conceived only against a ground where there is no order. Consequently, moral order can only be understood against the chaos of nondirected selfishness. The possibility to do evil is a condition for doing good.

The most obvious form of Schellingian evil resembles Kant's (2005, 55-56) idea of radical evil, where one subordinates the maxim demanded by the universal moral law to an arbitrary subjective desire-based maxim. In Schelling's terminology, instead of subordinating one's selfhood and personality based on the dark ground of existence to the service of the universal order, one tries to create one's own order from within. Jihad clearly represents this attempt to elevate the ground independently of the existing universal order. It claims that the sole truth is to be found in a particular tradition, and all who question that truth are enemies of it. Evil definitely exists for Jihad, but it is never really faced existentially, and in this sense it is denied. For Jihad, evil is always in the 'other.' Jihadist thought can recognize evil in oneself at best as 'the other inside me,' possibly even as a demon external to oneself, or as "sin" which is cured by punishing oneself, as if this "sinful" part was external to one's true identity.

Lawrence stresses that there is, however, another form of evil in Schelling's theory which does not fit with Kant's view or with the Enlightenment spirit in general. In fact, according to Lawrence, Kant's thought as such comes close to representing this form of evil from the Schellingian viewpoint (Lawrence, 2004, 175). The form of evil in question is the evil represented by McWorld. From the Western viewpoint it is not hard to see what evil is in Jihad. Jihad will not accept anything other than its own highly limited, and one could say also distorted, viewpoint. As Lawrence notes, 'the case of McWorld is harder to assess. Although its moving principle is clearly creed, its cosmopolitan emphasis on toleration and inclusiveness seems to give it a moral advantage - until one realizes that its goal is still domination' (Lawrence, 2004, 168). In order to understand what Lawrence means here by domination, we must return to the way 
McWorld denies evil.

There is a long tradition of Western philosophy in which evil is ultimately explained away; in Christian metaphysics as a privation of good, and later in secular thinking by means of natural explanations. As Lawrence crudely puts it: 'Instead of evil, we have problems. And for problems, explanations can be found....A given problem (for example melancholy) has a given solution (for instance, Prozac)" (Lawrence, 2004, 169). Lawrence's example of Prozac is naïve, but what if we instead think of 'a just and egalitarian society, free of exploitation'? Even Kant (2005, 33-35), who actually admitted the reality of evil, argued that 'the highest good' - a perfectly moral order with the happiness it deserves - must be possible. In Schelling's view, however, it is not possible to wipe away evil entirely because:

the unruly lies ever in the depths as though it might again break through, and order and form nowhere appear to have been original, but it seems as though what had initially been unruly had been brought to order. (Schelling, 1992, 34)

To engage in active moral evil, as Jihad does, is not the only form of imbalance between existence and its ground in Schelling's theory. If Jihad dives to the depths of the ground, losing its touch with the universal moral imperatives, McWorld denies that the lawful reality is dependent on a chaotic and unruly ground. The domination Lawrence associates with McWorld is the attempt to force everything into the box of rational understanding and to deny that there is always what Schelling $(1992,34)$ calls 'the irreducible remainder,' the real which can never be reached entirely by understanding based on ideas.

Additionally, this subtle form of domination is linked with the active explicit domination, usually associated with Jihad. Although Pauli Pylkkö's traditionalist, allegedly Schellingian statement that 'Western ethics is a civilized name for genocide' (Pylkkö, 2004, 218) is undoubtedly a gross exaggeration - to put it mildly - there might still be an important grain of truth in it. It is, after all, the modern Western culture that is responsible for the world-wide colonialism of the past centuries and the structural oppression of contemporary capitalism, each spread in the name of our most noble ideals of the time. Lawrence's argument seems to be that Jihad is in a sense already present in McWorld (and vice versa):

From Schelling's point of view, evil already exists in the epistemological act whereby the knowing subject casts all nature outside itself, transforming it into an object of scientific 
understanding and technological manipulation. This is the tacit and seemingly innocuous evil of McWorld. It is carried to a higher power when it involves the objectification and manipulation of other human beings. Jihad's emotionally charged loathing, 'the other tribe is filth', is the local and (once televised) highly conspicuous version of what unfolds silently and universally in McWorld's dispassionate reduction of humanity to 'resource' and 'consumer'. The irony is that the former serves as the ground and justification of the latter: fear of Jihad is the origin of McWorld. (Lawerence, 2004, 175)

In what follows I will explicate my argument that Schelling's metaphysics of evil can be read as a theory of recognition of which self-recognition is an essential element.

\section{Schellingian Recognition}

It might be argued that Jihad and McWorld are such different mentalities that no proper recognition between them is possible. However, this view misses that Jihad and McWorld actually already intensively recognize each other, but in the form of pathological recognition where only the evil of the other counts. It is evident that proper recognition must not exclude either criticizing or even condemning, but if the other party is only criticized and condemned, any constructive outcome is unlikely to appear. The condemned party may even build their identity around an 'evil' image. As the examples of school shooters and terrorists all around the world demonstrate, people often choose to be hated and feared rather than to be considered ridiculous at the very core of their identity. It seems that a minimal requirement for judging something as evil in an adequate way must be what Adam Morton has named the criterion of reflexiveness: 'a theory of evil should help us to understand how we can be seen as evil' (Morton, 2004, 8).

Richard Bernstein presents a similar argument in his book The Abuse of Evil - The Corruption of Politics and Religion since 9/11 where he analyzes the terrorism discourse in the USA after the 9/11 strikes and the role of the concept of evil in this discourse. According to Bernstein, the terrorism discourse reveals 'a clash of mentalities' between those who 'find rigid moral absolutes appealing, those who think that nuance and subtlety mask indecisiveness' and those 'who approach life with a more open, fallibilistic mentality - one that eschews the quest for absolute certainty' (Bernstein, 2008b, 16-17). Bernstein naturally advocates the latter mentality and names it 'pragmatic fallibilism' after the American pragmatists such as Peirce, Dewey and James. He cites Hilary Putnam, who has summarized the central 
theses of pragmatism in three principles: (1) antiskepticism, (2) fallibilism, and (3) the lack of a fundamental dichotomy between facts and values (Bernstein, 2008b, 27).

Even though Schelling can hardly be counted as pragmatist, he clearly shares the same ideas that Bernstein values in his notion of 'pragmatic fallibilism,' at least in the present context. According to Bernstein, pragmatic fallibilism 'does not raise skeptical doubts about the very possibility of knowledge' (Bernstein, 2008b, 30). Likewise Schelling takes it for granted that there are moral truths concerning good and evil, and we have some access to these truths. However, 'fallibilism does raise doubts about the very possibility of absolute incorrigible knowledge' (Bernstein, 2008b, 31). Also, Schelling argues that our moral claims are never derived from alleged first unquestionable premises fully transparent to rationality, but that they are based on a dark and irrational ground, which makes a fixed eternal system of moral truths even metaphysically impossible for Schelling. The pragmatists' third premise - the rejection of the fundamental dichotomy between facts and values - does not 'reject the idea that there are facts' (Bernstein 2008b, 30). Rather it aims 'to emphasize the ways in which our interests and values shape what we take to be the facts in a given context' (Bernstein, 2008b, 30). Schelling's system of freedom is pragmatic in this sense. It is meant to be a tool by which we guide ourselves in this actual reality, not a 'neutral' description of reality itself. This is exemplified in Schelling's famous statement that 'God is a life, not a mere thing' (Schelling, 1992, 84).

Schelling even has a metaphysical argument for why one must not be self-righteous about one's own goodness and the incurable evilness of the other. The belief in the final rationality of Western ideals and in the irrationality of religious jihadists commits the error of McWorld - it forgets that 'the unruly lies ever in the depths as though it might again break through, and order and form nowhere appear to have been original, but it seems as though what had initially been unruly had been brought to order" (Schelling, 1992, 34). It is not metaphysically possible for Schelling that good is entirely separated from evil in an exact, rational manner. The possibility of evil is what makes the good lively and real instead of a mere abstract ideal, for 'the basis of evil must...not only be founded on something positive, but rather on the highest positive being which nature contains' (Schelling, 1992, 44-45). And because man is a finite being, the possibility of evil is always a real threat for him.

The bad faith of McWorld is revealed at least when it's rationalistic explaining away of evil turns into jihadist fanaticism, which could be interpreted as having happened in the USA after the 9/11 strikes. Another similar large-scale example would be the rise of National Socialism in the 
lead up to and during World War II. C.G. Jung (1995, 174-180) no doubt had something similar to Lawrence's interpretation of Schelling in mind when he suggested that Nazism represents the shadow of modern Western rationalism. When the ground and the possibility of evil therein is suppressed, it finally breaks through as actual evil. One never knows oneself perfectly, and when one denies this existential insecurity, what is denied tries to break its way through into consciousness, eventually appearing as if it had become a being of its own. On the other hand, Jihad is also based on bad faith. It is constantly on the verge of falling into the false universalism it loathes in McWorld. Although the official message of Jihad is one of simply protecting one's own tradition, strong traditionalism practically always includes an element of world-conquering. New enemies are sought immediately after the possible, real threat is defeated. The best enemy is the one that cannot be defeated because it allows one to keep 'war as an emblem of identity' (Barber, 1992, 5) forever.

It might therefore be that the different cultural sets of values that characterize Jihad and McWorld do not contradict each other at the most fundamental level, but that where this seems hopelessly to be the case this is ultimately due to bad faith in one's own values. A Schellingian account of recognition would stress a strong link between recognition and selfrecognition. It is the latent element of false universalism in Jihad which makes it fight against all universalism as if universalism as such would destroy the liveliness of a particular tradition. On the other hand, the concrete terror Jihad has practiced against McWorld is hardly the sole cause of the moral rage against Jihad. Rather, acts such as the 9/11 attacks prove in a tangible enough way that the world cannot be made entirely safe and predictable. If the ground, with its constant possibility of ever new forms of evil is not recognized in a constructive way, it will make itself heard in a more destructive way.

Many readers may be struck by the affinity of Schelling's ideas to those of Hegel's, which have also already gained wide attention in the context of recognition. However, Lawrence reminds us that "to understand Schelling is above all to understand that he is not Hegel: ontological polarity can never be resolved in a developmental process" (Lawrence, 2004, 168). Schelling does not offer a normative but a metaphysical theory of evil and recognition. This is also of course the reason why Schelling has been heavily criticized and not traditionally taken as a serious rival of Hegel. For example, according to Michelle Kosch, Schelling has 'rendered himself incapable of telling us what we ought to do and why' (Kosch, 2006, 101). But if there is something McWorldish operative in Western thinking in general, then Schelling's holistic and non-analytical theory of evil may be a healthy alternative to theories that want to define good and evil exactly and tell us 
precisely how the good should be pursued. Moral questions relate directly to existential questions, and existential questions relate intimately to metaphysical questions of finitude, freedom, time and contingency. Schelling can no doubt be read in a way in which his metaphysics only hinder the consideration of what the proper concrete moral and political answers could be to the problems described here, but he can also be read as someone who investigates in a proper way the deep connections between moral, existential and metaphysical questions:

I believe I could show how Schelling makes it possible to be simultaneously politically radical and culturally conservative, whereby by 'conservative' I do not mean Matthew Arnoldesque fixation on the past, but something else entirely: the realization that the deepest moments of culture can only be comprehended in a response that is so thoroughly creative that it opens up access to the future. To understand that relationship is to understand 'ground' by Schelling. (Lawrence, 2004, 189)

I take Lawrence's message to be that there is something important to be learned both for classical Western humanitarian thinking and for ways of thinking in which tradition, instead of universal ethical standards, is put in the highest place. Both may engage in what Schelling would call a wrong relation between existence and its ground. Existence is always a system with universal laws, but also a system based on an unruly ground. McWorld does not want to face the ground at all, because this would demonstrate that what McWorld sees as eternal and entirely right must still always contain the possibility of evil. With this denial, the possibility of evil becomes actualized in the form of structural oppression of everything that seriously questions the McWorld way of life. Jihad instead refuses to channel the liveliness of the ground to any universal purposes, and thereby it finally lacerates itself, because everything particular and vital can gain its vitality and meaning only in relation to the world as a whole. Both Jihad and McWorld have an unhealthy relation to the openness of the future that Schelling describes as the becoming from ground to existence. While Jihad clings directly to the past in its blind worship of tradition, McWorld also makes this mistake by thinking that it can calculate the future from what is already past. $^{2}$

Olli Pitkänen (olli.p.pitkanen@student.jyu.fi) is a master of social sciences who works as a graduate student at the University of Jyväskylä. His ongoing $\mathrm{PhD}$ thesis deals with the possibility of a metaphysical conception of evil in contemporary philosophy. 


\section{Bibliography}

Barber, B. (1992) 'Jihad vs. McWorld' The Atlantic March 1992, accessed 31 October 2014 http://www.theatlantic.com/magazine/archive/1992/03/jihad-vsmcworld/303882/

Bernstein, R. (2008a) Radical Evil - A Philosophical Interrogation New Hampshire: Polity Press

Bernstein, R. (2008b) The Abuse of Evil - The Corruption of Politics and Religion since 9/11 Norfolk: Polity Press

Bowie, A. (2006) Schelling and Modern European Philosophy UK: Routledge

Corriero, E. C. \& Dezi, A. (eds.) (2013) Nature and Realism in Schelling's Philosophy Torino: Accademia University Press

French, P. \& Wettstein, H. (eds.) (2012) The Concept of Evil Boston \& Oxford: Blackwell Publishing

Ffytche, M. (2013) The Foundation of the Unconscious - Schelling, Freud and the Birth of the Modern Psyche UK: Cambridge University Press

Freydberg, B. (2008) Schelling's Dialogical Freedom Essay USA: State University of New York Press

Garrard, E. \& McNaughton, D. (2012) 'Speak No Evil?' in P. French \& H. Wettstein (eds.) The Concept of Evil Boston \& Oxford: Blackwell Publishing, pp. 1-17

Grant, I. H. (2008) Philosophies of Nature After Schelling Cornwall: Continuum

Habermas, J. (2004) 'Dialectical Idealism in Transition to Materialism: Schelling's Idea of a Contraction of God and its Consequences for the Philosophy of History' in J. Norman \& A. Welchman (eds.) The New Schelling Wiltshire: Continuum, pp. 43-89

Heidegger, M. (1985) Schelling's Treatise on the Nature of Human Freedom (trans. J. Stambaugh), USA: Ohio University Press 
Hösle, V. (1992) Praktische Philosophie in der modernen Welt München: Verlag C.H. Beck

Jung, C. G. (1995) 'Fight with the Shadow' in M. Stein (ed.) Jung on Evil USA: Princeton University Press, pp. 174-180

Kant, I. (2005) Religion within the Boundaries of Mere Reason and Other Writings (trans. A. Wood \& G. Di Giovanni), Cambridge: Cambridge University Press

Kosch, M. (2006) Freedom and Reason in Kant, Schelling and Kierkegaard UK: Clarendon Press

Lawrence, J. (2004) 'Schelling's Metaphysics of Evil' in J. Norman \& A. Welchman (eds.) The New Schelling Wiltshire: Continuum, pp. 167-189

Lawrence, J. (2005) 'Philosophical Religion and the Quest for Authenticity' in J. Wirth (ed.) Schelling Now - Contemporary Readings USA: Indiana University Press, pp. 13-30

Marquard, O. (2004) 'Several Connections between Aesthetics and Therapeutics in Nineteenth-century Philosophy' in J. Norman \& A. Welchman (eds.) The New Schelling Wiltshire: Continuum, pp. 13-29

McGrath, S. J. (2012) The Dark Ground of the Spirit - Schelling and the Unconscious Cornwall: Routledge

Metzl, J. (1996) 'A Review of Jihad vs. McWorld by Benjamin Barber' Harvard Journal of Law \& Technology vol. 9, no. 2

Morton, A. (2004) On Evil Cornwall: Routledge

Norman, J. \& Welchman, A. (eds.) (2004) The New Schelling Wiltshire: Continuum

Ostaric, L. (ed.) (2014) Interpreting Schelling - Critical Essays United Kingdom: Cambridge University Press

Pylkkö, P. (2004) 'Schelling ja panteismikiista' in F. W. J. Schelling Ihmisen vapaudesta Kiel: Uuni, pp. 141-222

Roberts, D. (2006) Kierkegaard's Analysis of Radical Evil Cornwall: Continuum 
Schelling, F. W. J. (1992) Philosophical Inquiries into the Nature of Human Freedom (trans. J. Gutmann), USA: Open Court

Schelling, F. W. J. (2004) Ihmisen vapaudesta (trans. P. Pylkkö), Kiel: Uuni

Shafer-Landau, R. (2004) Whatever Happened to Good and Evil? USA: Oxford University Press

Stein, M. (ed.) (1995) Jung on Evil USA: Princeton University Press

Svendsen, L. (2010) A Philosophy of Evil USA: Dalkey Archive Press

Watson, J. (2004) Schelling's Transcendental Idealism Leipzig: Adamant Media Corporation

Welchman, A. (2013) 'Schelling's Moral Argument for a Metaphysics of Contingency' in E. C. Corriero \& A. Dezi (eds.) Nature and Realism in Schelling's Philosophy Torino: Accademia University Press, pp. 27-54

Wirth, J. (2003) The Conspiracy of Life - Meditations on Schelling and His Time USA: State University of New York Press

Wirth, J. (2005) Schelling Now - Contemporary Readings USA: Indiana University Press

Žižek, S. (2007) The Irreducible Remainder - On Schelling and Related Matters Surrey: Verso

\section{Endnotes}

${ }^{1}$ All italics within quotations are from the original text unless otherwise stated.

2 I would like to thank all the members of the "Pathologies of Recognition" project, especially Arto Laitinen, Arvi Särkelä and Jarno Hietalahti for helpful comments on various drafts of this paper. I would also like to thank Alison Beale for proof-reading the final draft. 